\title{
Personalised Advanced Therapies in Parkinson's Disease: The Role of Non-Motor Symptoms Profile
}

\author{
Valentina Leta ${ }^{1,2,+}+\mathbb{D}$, Haidar S. Dafsari ${ }^{3,+}+\mathbb{D}$, Anna Sauerbier $1,2,3$, Vinod Metta ${ }^{1,2}$, Nataliya Titova ${ }^{4,5}$, \\ Lars Timmermann ${ }^{6}$, Keyoumars Ashkan ${ }^{7}$, Michael Samuel ${ }^{2}$, Eero Pekkonen ${ }^{8}$, Per Odin ${ }^{9}$, Angelo Antonini ${ }^{10}{ }^{\infty}$,

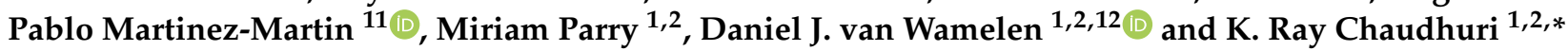

1 Department of Basic and Clinical Neurosciences, Institute of Psychiatry, Psychology \& Neuroscience, King's College London, London SE5 9RT, UK; valentina.1.leta@kcl.ac.uk (V.L.); anna.sauerbier@uk-koeln.de (A.S.); vinod.metta@nhs.net (V.M.); miriamparry@nhs.net (M.P.); daniel.van_wamelen@kcl.ac.uk (D.J.v.W.)

2 Parkinson's Foundation Centre of Excellence, King's College Hospital, London SE5 9RS, UK; m.samuel@nhs.net

3 Department of Neurology, Faculty of Medicine, University of Cologne, 50937 Cologne, Germany; haidar.dafsari@uk-koeln.de

4 Department of Neurology, Neurosurgery and Medical Genetics, Federal State Autonomous Educational Institution of Higher Education «N.I. Pirogov Russian National Research Medical University», Ministry of Health of the Russian Federation, 117997 Moscow, Russia; nattitova@yandex.ru

5 Department of Neurodegenerative Diseases, Federal State Budgetary Institution «Federal Center of Brain and Neurotechnologies», Ministry of Health of the Russian Federation, 117997 Moscow, Russia

6 Department of Neurology, University Hospital of Giessen and Marburg, Campus Marburg, 35043 Marburg, Hessen, Germany; lars.timmermann@uk-gm.de

check for

updates

Citation: Leta, V.; Dafsari, H.S.; Sauerbier, A.; Metta, V.; Titova, N.; Timmermann, L.; Ashkan, K.; Samuel, M.; Pekkonen, E.; Odin, P.; et al. Personalised Advanced Therapies in Parkinson's Disease: The Role of Non-Motor Symptoms Profile. J. Pers. Med. 2021, 11, 773. https://doi.org/ 10.3390/jpm11080773

Academic Editor: Chiara Villa

Received: 1 July 2021

Accepted: 26 July 2021

Published: 7 August 2021

Publisher's Note: MDPI stays neutral with regard to jurisdictional claims in published maps and institutional affiliations.

Copyright: (c) 2021 by the authors. Licensee MDPI, Basel, Switzerland. This article is an open access article distributed under the terms and conditions of the Creative Commons Attribution (CC BY) license (https:// creativecommons.org/licenses/by/ $4.0 /)$.
7 Neurosurgical Department, King's College Hospital Foundation Trust, London SE5 9RS, UK; k.ashkan@nhs.net

8 Department of Neurology, University of Helsinki, 00029 HUS Helsinki, Finland; eero.pekkonen@hus.fi

9 Division of Neurology, Department of Clinical Sciences Lund, Lund University, P663+Q9 Lund, Sweden; per.odin@med.lu.se

10 Parkinson and Movement Disorders Unit, Department of Neuroscience, University of Padua, 35138 Padua, Italy; angelo.antonini@unipd.it

11 Centre for Networked Biomedical Research in Neurodegenerative Diseases (CIBERNED), Carlos III Institute of Health, 28031 Madrid, Spain; pmm650@hotmail.com

12 Department of Neurology, Donders Institute for Brain, Cognition and Behaviour, Radboud University Medical Centre, 6500HB Nijmegen, The Netherlands

* Correspondence: ray.chaudhuri@kcl.ac.uk; Tel.: +44-20-3299-8807

+ These authors contributed equally to this work.

Abstract: Device-aided therapies, including levodopa-carbidopa intestinal gel infusion, apomorphine subcutaneous infusion, and deep brain stimulation, are available in many countries for the management of the advanced stage of Parkinson's disease (PD). Currently, selection of device-aided therapies is mainly focused on patients' motor profile while non-motor symptoms play a role limited to being regarded as possible exclusion criteria in the decision-making process for the delivery and sustenance of a successful treatment. Differential beneficial effects on specific non-motor symptoms of the currently available device-aided therapies for PD are emerging and these could hold relevant clinical implications. In this viewpoint, we suggest that specific non-motor symptoms could be used as an additional anchor to motor symptoms and not merely as exclusion criteria to deliver bespoke and patient-specific personalised therapy for advanced PD.

Keywords: Parkinson's disease; device-aided therapies; non-motor symptoms; personalised medicine; apomorphine; levodopa-carbidopa intestinal gel; deep brain stimulation

\section{Advanced Parkinson's Disease: The Clinical Scenario}

Parkinson's disease (PD) is a heterogenous syndromic disorder with a complex natural history, spanning prodromal to palliative stages [1,2]. While early motor phases of PD 
can be effectively managed by oral and transdermal dopamine replacement therapies, treatment of the more advanced phases remains a challenge, partly complicated by the requirement to choose which device-aided therapies (DAT) to offer to which patients, including levodopa-carbidopa intestinal gel infusion (LCIG) with or without entacapone, subcutaneous apomorphine infusion (APO), and deep brain stimulation (DBS). An optimal therapeutic choice is important as advanced PD is associated with motor and non-motor complications which may be refractory to standard oral/transdermal therapy negatively affecting quality of life [3-6]. International consensus and standard guidelines have attempted to address ideal DAT selection, but the latter still remains an unmet need [7-9]. A recent initiative based on an international Delphi-panel approach identified key motor, non-motor, and functional indicators of advanced PD [10], externally validated in the OBSERVE-PD study [11]. This has led to the development of the '5-2-1' paradigm ( $\geq 5$-times oral levodopa doses/day, $\geq 2 \mathrm{~h}$ of 'off' symptoms/day, $\geq 1 \mathrm{~h}$ of troublesome dyskinesia/day) to identify motor aspects of advanced PD and ensure timely referral for DAT initiation [10]. The interim analysis of DUOGLOBE, an observational study evaluating the long-term effectiveness of LCIG in patients with advanced PD, showed that only $20 \%$ of patients met all of the 5-2-1 criteria, but $98 \%$ met at least one criterion, highlighting the need for further refinement and personalisation of DAT selection [12].

A clinically relevant issue is the debate on whether earlier (than currently adopted in clinical practice) initiation of DAT may be beneficial for patients with PD. The EARLYSTIM study as well as the post-hoc analysis of the GLORIA registry have explored an earlier introduction of DBS and LCIG, respectively, but appropriate timing of DAT initiation largely remains an area of debate [13-15]. Moreover, older patients ( $\geq 75$ years), for whom DBS is often not considered because of risk-benefit uncertainty, may nonetheless benefit from a modified approach involving DBS of several nuclei [16]. Another emergent debate is focused on how non-motor symptoms (NMS) may guide DAT selection for patients with $\mathrm{PD}$ as a positive inclusion criterion, rather than being used purely as an exclusion criterion, e.g., severe depression as a contraindication for DBS and severe hallucinations for APO.

Finally, also in relation to initiatives of providing earlier initiation of DAT in patients with PD, the relatively high costs of DAT need to be taken into account. Here, the societal impact of advanced PD is considerable as the $20 \%$ most affected patients are responsible for around $70 \%$ of secondary care costs [17]. The costs of DAT can be considerable, but NMS have not been taken into account in cost-effectiveness analyses [18]. This is a relevant observation as NMS contribute at least equally, if not more, to quality of life as motor symptoms $[19,20]$. Additionally, motor fluctuations, the most common indication for DAT, are often accompanied by non-motor fluctuations, adding to perceived quality of life [21,22]. Thus, it seems reasonable to include NMS in the decision to initiate DAT in patients with PD, especially for those with only moderate motor symptoms but severe non-motor burden [23].

Therefore, in this viewpoint, we will focus on the emerging role of the non-motor profile integral to the choice and outcomes of personalised medicine [1] when delivering DAT in PD. We aim to delineate the emerging field of non-motor indications for DAT and discuss possible implications for clinical practice.

\section{Current Use of Non-Motor Symptoms in Device-Aided Therapies Selection}

NMS have been proposed as criteria to consider for use of DAT; however, they are not considered in most country-based guidelines by licensing authorities or are merely used as exclusion criteria. The latter has been reviewed as part of the NAVIGATE PD initiative [7], for instance, and NMS constitute both relative and absolute contraindications for certain DAT while data suggests NMS could be improved by DAT. An absolute contraindication (in most countries) for all DAT is severe dementia, whereas non-motor aspects representing relative contraindications are more diverse. For APO and LCIG these include impulse control disorder and dopamine dysregulation syndrome, along with mild to moderate cognitive dysfunction; for DBS the main non-motor contraindications are severe depression 
and clinically relevant cognitive impairments [7,24]. Moreover, presence of symptomatic orthostatic hypotension, excessive daytime sleepiness, and severe hallucinations could be considered exclusion criteria for APO [25].

\section{Device-Aided Therapies and Differential Effect on Non-Motor Symptoms}

While therapeutic decisions and research on DAT have largely focused on the influence and effect on motor symptoms, NMS are an integral feature of PD and, therefore, should play an active part in the decision-making process to select the ideal DAT for patients with PD $[7,10]$. Although APO, LCIG and bilateral subthalamic nucleus (STN) DBS have been available for many years for the treatment of PD in many countries, head-to-head comparative studies are limited. Following on from the original EuroInf study [26], the EuroInf 2 study is the first and only study concurrently comparing all three DAT [27]. Although open-label in its design, it offers Class IIb evidence on the differential effects of these DAT on NMS measured by the NMS scale (NMSS) total burden and its domain's scores. In agreement with other studies, all three therapeutic options confirmed an improvement in motor complications, Hoehn and Yahr stage and quality of life [26-32]. Although all three DAT decreased total NMS burden, interestingly, each treatment appeared to have a bias towards specific NMS thus providing some early indications of varied responsiveness to each therapy. For instance, in this cohort of 173 patients, APO decreased the attention/memory domain scores, while bilateral STN-DBS and LCIG did to a lesser extent which was not statically significant. Nonetheless, it needs to be acknowledged that patients with cognitive problems would be excluded a priori from receiving DBS. Similarly, in this study patients receiving APO had higher NMSS attention/memory baseline scores compared to the other groups, leaving more room for improvement. Data on patients with severe attention/memory problems are not available. On the other hand, DBS and LCIG appeared to reduce the urinary and gastrointestinal domains scores, respectively. All three treatment options decreased the mood/apathy and miscellaneous domains scores, the latter including weight changes, altered thermoregulation and olfaction as well as unexplained pain. Improvements here were heterogeneous, and while APO reduced weight change-related scores, LCIG and DBS improved most of the symptoms contained within the miscellaneous domain. Aspects of sleep dysfunction and fatigue as measured by the NMSS also improved with both LCIG and bilateral STN-DBS, but not after APO initiation. Finally, there is evidence to suggest that APO and bilateral STN-DBS decrease the perceptual problems and hallucinations domain scores, although typically these are considered contra-indications [10]. The mechanisms behind these associations need to be further elucidated; however, it is possible to argue that, for instance, historical presence of visual hallucinations which are mainly drug-induced, and which might subside after drug withdrawal at the expense of a troublesome motor worsening, might benefit from DAT initiation. Finally, combined DAT-related data is also emerging, and may help us to overcome specific issues [33-38].

\subsection{Non-Motor Effects of Deep Brain Stimulation}

Important conceptual advances may hold promise in relation to the delivery of personalised medicine and DAT in PD [2]. In addition to the abovementioned EuroInf studies, this is exemplified by several studies that have been conducted on the non-motor effects of DBS, showing improvements in several non-motor areas that have been reviewed elsewhere [39-44]. In brief, a recent meta-analysis, including 48 studies with mainly 12-month follow-up data, suggested post-STN-DBS improvements of depression and anxiety-related symptoms but increased apathy [41]. Another meta-analysis of seven studies with followup data ranging from three to 24 months showed post-STN-DBS improvements in sleep quality and restless leg syndrome; however, a high degree of heterogeneity among studies was reported $[39,44,45]$, and few studies have investigated the effect of STN-DBS on REM sleep behaviour disorder [42,46]. Another recently published review summarised post-DBS positive outcomes related to urinary dysfunction (mean bladder volumes at desire and 
urge point to void), while controversial and limited data are available in relation to sexual, cardiovascular, thermoregulatory and gastrointestinal dysfunction [40]. Finally, even though presence of dementia is a contraindication for DBS, a systematic review of 13 studies showed that although there was a decline in verbal fluency and attention domains of cognition, other cognitive functions remained unchanged over a follow-up period ranging from six months to eight years [43]. It needs to be acknowledged that most included studies had small cohort sizes and heterogenous outcome measures.

Further advancements in relation to personalised medicine with DBS might be achieved by directing neurostimulation to specific parts of the basal ganglia and leveraging their specific connectivity profiles [47-49].

More theoretical approaches, such as adaptive DBS, have been developed as a method where DBS is turned on and off according to a closed-loop feedback signal recorded from the tissue surrounding the stimulating electrode. This may develop into personalised approach if it can show to activate DBS at times of necessity and reduce it at times of quiescence, for example in sleep, with the aim of a more physiological treatment and potentially reducing the frequency for battery replacements in non-rechargeable systems. Presently, limitations to the clinical application of adaptive DBS are: (1) Tremor frequency, beta-band and other oscillations required for the closed-loop feedback arc of adaptive DBS are not recordable in all patients with PD [50]; (2) beta-band activity represents not only pathological alterations, but is also modulated by physiological functions [51,52] (3) pathological tremor frequency and beta-band oscillations may, in some patients, reflect tremor, bradykinesia and rigidity, but not NMS [53]; (4) motor symptoms can fluctuate at different times during the course of the day than non-motor fluctuations [21,22]. As such, situations may arise in which the neurostimulation is not active because tremor frequency and beta-band oscillations cannot be detected, but the patient nonetheless presents with NMS such as pain or depressed mood. Therefore, studies are needed to investigate the effect of adaptive DBS on quality of life and NMS, not only motor symptoms [54].

\subsection{Non-Motor Effects of Levodopa-Carbidopa Intestinal Gel Infusion}

There is robust evidence on the effect of LCIG on NMS. In 2015, a systematic review identified eight open-label studies confirming that LCIG improved total NMS burden after a follow up period ranging from six to 25 months, with specific positive effects on sleep and autonomic dysfunction, and particularly gastrointestinal issues measured by the NMSS [55]. Additionally, more recent reviews have highlighted the non-motor effect of LCIG where a general improvement in the non-motor burden was noted [56,57]. Studies included in these reviews were, among others, the GLORIA registry, whose 24-month follow up data showed a remarkable beneficial effect of LCIG on sleep disturbances, apathy, and gastrointestinal dysfunction as measured by the NMSS [29], and the interim analysis of the DUOGLOBE study, where an overall improvement in the NMS total burden was also shown after only six months [12]. Additional open labels studies with 6-month followup data showed a post-LCIG improvement in NMS total burden, including reduction of the cardiovascular, attention/memory, urinary and miscellaneous domains scores of the NMSS [26,58]. Interestingly, the baseline total burden of NMS in PD can predict a robust total non-motor response to LCIG therapy at two years follow up. This observation can underpin DAT selection with an NMS focus, specifically when considering personalised LCIG therapy for instance [59].

\subsection{Non-Motor Effects of Apomorphine Subcutaneous Infusion}

Although APO has been in use longest compared with DBS and LCIG (APO became available on the European market in the early 1990s), data regarding APO and selection of this device-aided therapy based on patients' non-motor profile is less obvious and the results from the double-blind TOLEDO study are awaited with interest [60]. However, several open-label and case report-based studies show that this treatment can have a beneficial effect on the NMS total burden as well as on specific non-motor areas, and these 
have been reviewed elsewhere [56,61,62]. In brief, there is evidence suggesting post-APO improvements in depression, anxiety, apathy, perceptual problems, cognitive impairment, sleep dysfunction (insomnia and restless leg syndrome), fatigue, urinary dysfunction (urinary frequency, urgency and nocturia), and gastrointestinal dysfunction (dribbling of saliva) as measured by the NMSS at both 6- and 12-month follow up [26,63]. The reported beneficial effect or tolerability of APO on mild visual hallucinations is of interest given that it is a dopamine D1 and D2 receptor agonist, and suggested underlying mechanisms include the associated reduction in oral medication and/or a psychotropic action of APO, possibly due to the piperidine moiety in its structure $[64,65]$. In addition, the potential beneficial role of APO on cerebral amyloid deposition is worth considering in relation to its positive modulatory effect on cognition $[26,63,66,67]$.

\section{Need for Personalised Treatment in Advanced Parkinson's: Clinical Cases}

Taking into account the distinct NMS effects of these three DAT, it can be postulated that the specific non-motor profile of patients with advanced PD may serve as an additional anchor to motor symptoms to deliver personalised medicine. Two illustrative clinical cases are presented in Figure 1 showing the different non-motor profile of two patients with advanced PD evaluated for DAT initiation.

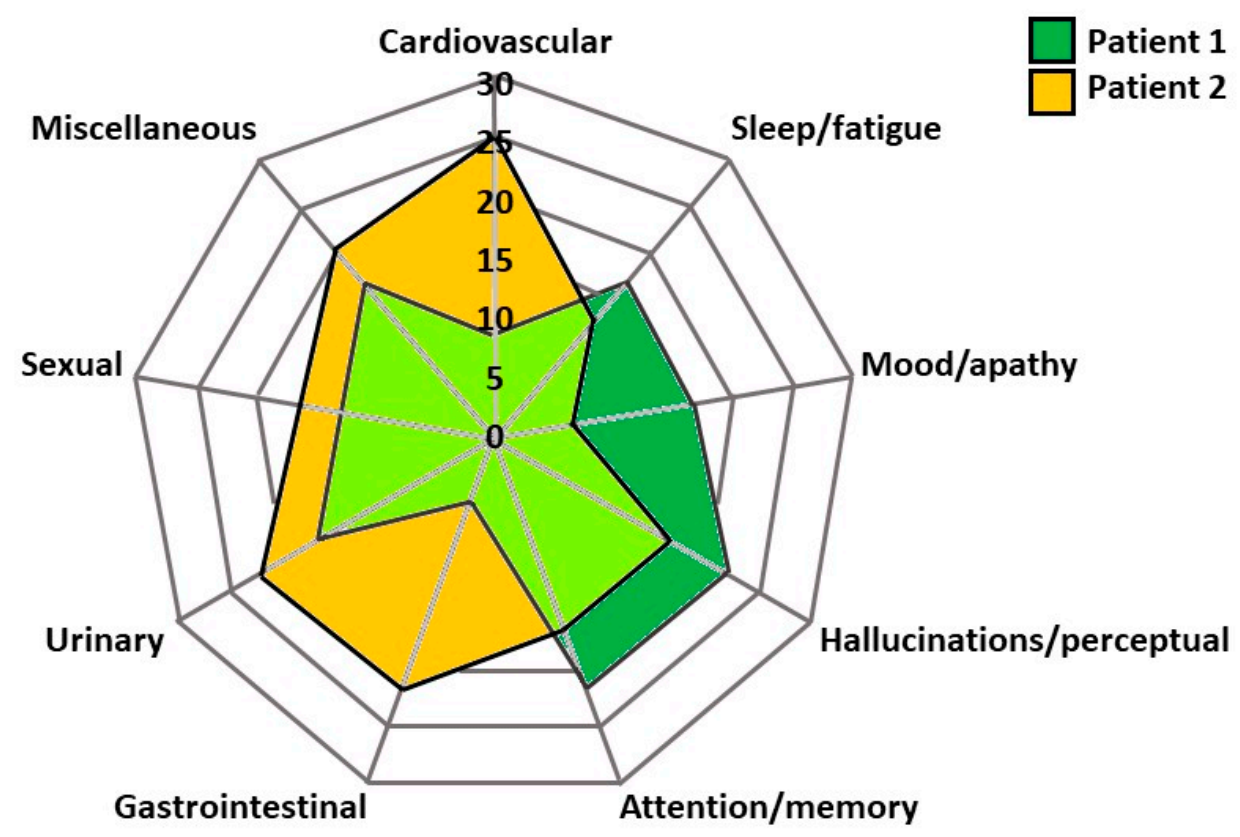

Figure 1. Radar chart of non-motor profile of two patients with advanced Parkinson's disease assessed for initiation of device-aided treatments. The radar chart is based on the Non-Motor Symptoms Scale (NMSS) domains scores obtained as part of routine clinical assessment. While patient 1's nonmotor profile is dominated by mild attention/memory issues as well as mild perceptual problems, patient 2's main complaint is dysautonomia, including cardiovascular, urinary and gastrointestinal dysfunction. Numbers represent the NMSS domains scores. The light green area represents the overlap in symptoms between the two patients.

The clinical assessment revealed that both patients suffered from motor complications including troublesome dyskinesia and motor fluctuations refractory to conventional therapies; in addition, the non-motor profile of patient 1 was dominated by mild cognitive decline and non-intrusive perceptual issues, whereas for patient 2, cardiovascular, urinary, and gastrointestinal dysfunction were particularly pronounced. On the basis of these two different non-motor profiles and according to the EuroInf 2 data, it can be argued that APO may represent the best therapeutic option for patient 1 , while, for patient 2 , APO may not be suitable as it may exacerbate pre-existing cardiovascular problems, including 
orthostatic hypotension. On the other hand, while LCIG may be useful to improve gastrointestinal symptoms, STN-DBS may be the best option to improve urinary dysfunction for patient 2. As such, it would be important to inquire which one of the two is the most troublesome/severe NMS to better tailor the decision-making process.

Other factors are also implicated in the delivery of personalised DAT in PD [2]. Evaluation of patient age, for instance, represents a key aspect in the assessment for DBS suitability; indeed, age $>70$ or 75 years is an exclusion criterion for DBS in some centres given the associated higher risk of complications [68]; nevertheless, biological age is more often taken into consideration than chronological age in addition to the fact that the impact of "healthy ageing" is growing [69]. Another relevant aspect of this decision-making process is the evaluation of comorbidities. For instance, poorly controlled diabetic patients with PD have a higher risk of developing skin infections and this should be considered in the evaluation for any DAT [70]. Other comorbidities, such as pre-existing significant and symptomatic peripheral neuropathy needs consideration for LCIG, impulse control disorder and intrusive psychosis (as opposed to mild non-intrusive psychosis) for APO, and severe depression or suicidal trends for DBS [7]. Last but not least, patient personality and preferences need to be taken into account: some active young patients may prefer a more invasive brain surgery than a percutaneous endoscopic gastrostomy in order to avoid carrying a visible infusion pump every day, and for a "quick fix" of dyskinesias and tremor [71]. Body weight has also emerged as an important aspect of the decision-making process [72]. Low body weight patients with advanced PD may develop pain, discomfort and worsening of postural problems with subsequent risk of falls when carrying a heavy infusion pump [73]. The advent of a smaller infusion pump with the new levodopacarbidopa-entacapone intestinal gel product now licensed for use in Sweden and Germany may represent a significant advance in this respect $[74,75]$. Whether this new product will have an impact on NMS similar to LCIG remains unexplored. Evaluating the ability of the patient and/or caregiver to handle the medication and the device, as well as daily skin hygiene, is also critical [73].

\section{Conclusions}

Device-aided therapies are now established worldwide for the management of advanced Parkinson's disease. While the emphasis of device-aided therapies selection remains based on the motor profile of patients with PD, non-motor symptoms have also been shown to play a part in the prognostic aspects of the successful delivery of these therapeutic options and are now included in the diagnostic algorithm of advanced PD. Considering the differential effect on non-motor symptoms of the currently available device-aided therapies, non-motor symptoms are relevant to delivering personalised medicine in Parkinson's disease. We envisage that the identification of different motor and non-motor phenotypes of Parkinson's may guide the delivery of personalised medicine in the advanced stage of the condition, perhaps guided by technology able to predict motor and non-motor responses to device-aided therapies on the basis of the patient-specific pre-intervention symptom's profile. We suggest that non-motor symptoms are an important enabler of the constituents of the "circle of personalised medicine" and offers a chance to deliver bespoke personalised therapy for advanced PD (Figure 2). 


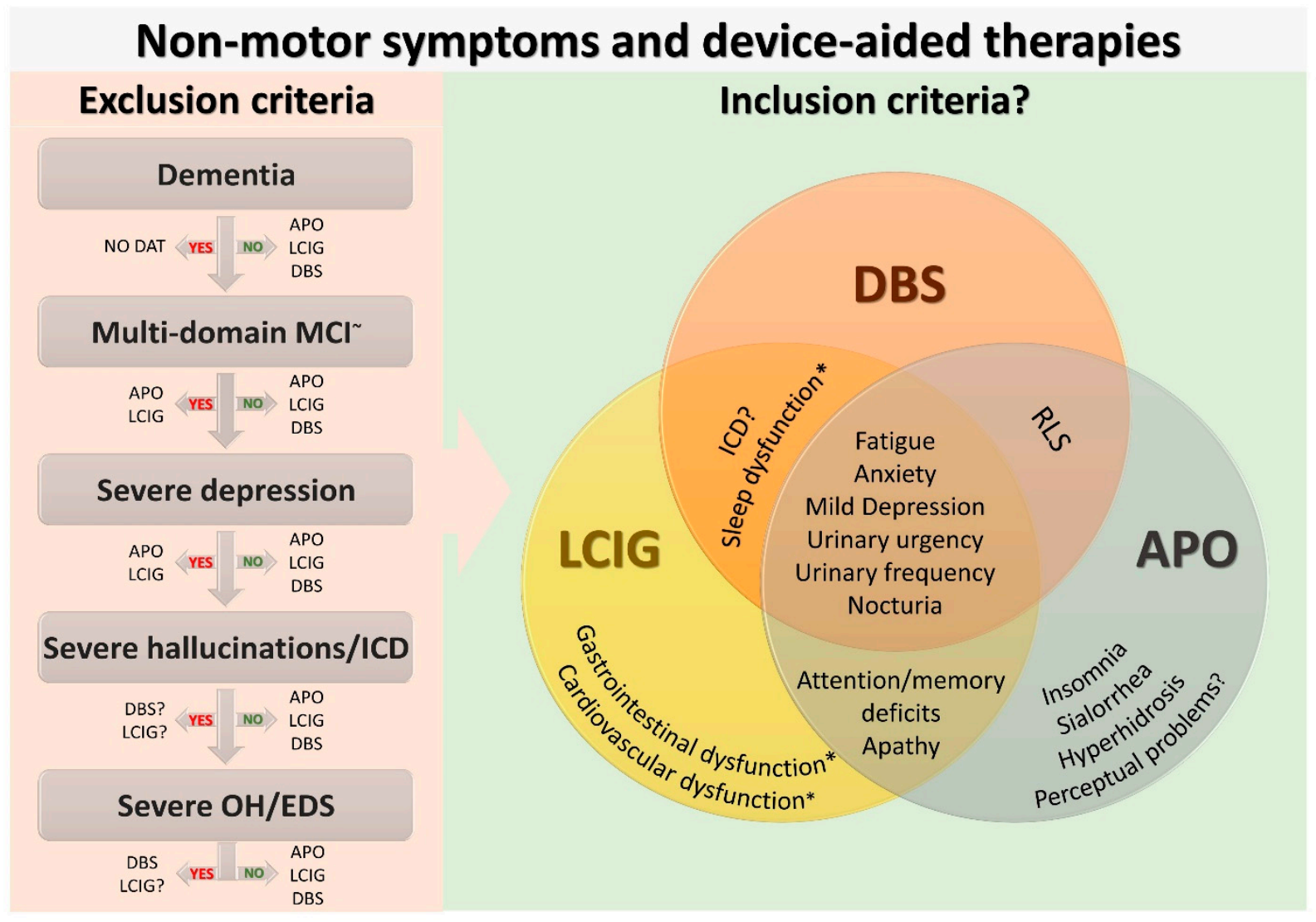

Figure 2. Non-motor enablers for a successful selection of device-aided therapy for patients with advanced Parkinson's disease. The figure shows non-motor exclusion and possible inclusion criteria for a successful patient initiation on deviceaided therapies. We emphasise that these conditions should not be considered an absolute contraindication or indication for

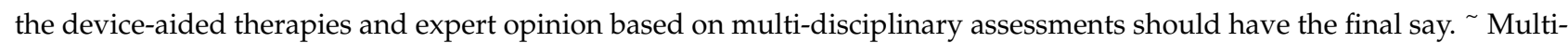
domain MCI with a predominant cortical pattern (e.g., memory, language, visuospatial); ${ }^{*}$ Further studies are needed to better clarify which aspect of sleep, gastrointestinal and cardiovascular dysfunction can improve after device-aided therapy initiation. Abbreviations: APO, apomorphine subcutaneous infusion; DAT, device-aided therapies; DBS, Deep brain stimulation; EDS, excessive daytime sleepiness; ICD, Impulse control disorder; LCIG, levodopa-carbidopa intestinal gel infusion; MCI; mild cognitive impairment; NMS, non-motors symptoms; $\mathrm{OH}$, orthostatic hypotension; RLS, Restless legs syndrome.

Author Contributions: Conceptualization, V.L., H.S.D., K.R.C.; writing—original draft preparation, V.L.; writing—review and editing, H.S.D., K.R.C., D.J.v.W., A.S., V.M., N.T., L.T., K.A., M.S., E.P., P.O., A.A., P.M.-M., M.P.; supervision, H.S.D., K.R.C. All authors have read and agreed to the published version of the manuscript.

Funding: The authors did not receive support from any organization for the submitted work.

Institutional Review Board Statement: Not applicable.

Informed Consent Statement: Not applicable.

Data Availability Statement: Not applicable.

Acknowledgments: The views expressed are those of the authors and not necessarily those of the NHS, NIHR or Department of Health. The authors acknowledge the support of the International Parkinson and Movement Disorder Society Non-Motor Parkinson's disease Study Group, the NIHR London South Clinical Research Network and the NIHR Biomedical Research Centre. The authors acknowledge Juliet Staunton for the proofreading of the manuscript. This article represents independent collaborative research performed by staff who are part funded by the NIHR Biomedical Research Centre at South London and Maudsley NHS Foundation Trust and King's College London. 
Conflicts of Interest: V.L. reports grants from Parkinson's UK and honoraria for sponsored symposia from UCB, Bial, Invisio, Profile and Britannia Pharmaceuticals, outside the submitted work. H.S.D. was funded by the EU Joint Programme-Neurodegenerative Disease Research (JPND), the Prof. Klaus Thiemann Foundation in the German Society of Neurology, the Felgenhauer Foundation, the KoelnFortune program of the Medical Faculty of the University of Cologne, and has received honoraria by Boston Scientific, Medtronic and Stadapharm, outside the submitted work. A.S. is funded by the Gusyk program and the Advanced Cologne Clinician Scientist program of the Medical Faculty of the University of Cologne and has received funding from the Prof. Klaus Thiemann Foundation, outside the submitted work. L.T. received payments as a consultant for Boston Scientific, honoraria as a speaker on symposia sponsored by UCB, Desitin, Boston Scientific, AbbVIE, Novartis, GlaxoSmithKline und DIAPLAN; the institution of L.T., not L.T. personally received funding by Boston Scientific, the German Research Foundation, the German Ministry of Education and Research and the Deutsche Parkinson Vereinigung, outside the submitted work. K.A. reports educational grant and honoraria from Medtronic and Abbott, outside the submitted work. M.S. has received educational support from Medtronic (paid to the institution), Parkinson's UK (via the UK DBS network), acts as a consultant for Abbott, and received honoraria from The Movement Disorders Society, outside the submitted work. E.P. reports the following disclosures outside the submitted work: consulting neurologist for Finnish Patient Insurance Centre; Standing Member of the MDS NonMotor Parkinson's Disease, Study Group; Consulting fees: NordicInfu Care AB, Abbvie, Zambon; Member of Advisory board: Abbvie; Lecture fees: Abbott, Abbvie, Nordic Infucare. P.O. has received honoraria for lectures and advice from AbbVie, Bial, Britannia, Kyowa, Nordic Infucare and Zambon, outside the submitted work. P.M.M. has received honoraria from National School of Public Health (ISCIII), Editorial Viguera and Takeda Pharmaceuticals for lecturing in courses; and from the International Parkinson and Movement Disorder Society (IPMDS) for management of the Program on Rating Scales, outside the submitted work. M.P. has received honoraria form AbbVie and Britannia Pharmaceuticals, outside the submitted work. D.J.v.W. received a grant, and consultancy, and speaker fees from Britannia Pharmaceuticals, speaker fees from Bial Pharmaceuticals, and consultancy fees from Invisio Pharma, outside the submitted work. K.R.C. reports advisory board for AbbVie, UCB, GKC, Bial, Cynapsus, Novartis, Lobsor, Stada, Medtronic, Zambon, Profile, Sunovion, Roche, Theravance, Scion, Britannia; honoraria for lectures from AbbVie, Britannia, UCB, Mundipharma, Zambon, Novartis, Boeringer Ingelheim; grants (Investigator Initiated) from Britania Pharmaceuticals, AbbVie, UCB, GKC, Bial; academic grants from EU, IMI EU, Horizon 2020, Parkinson's UK, NIHR, PDNMG, EU (Horizon 2020), Kirby Laing Foundation, NPF, MRC, Wellcome Trust, outside the submitted work.

\section{References}

1. Titova, N.; Chaudhuri, K.R. Non-motor Parkinson disease: New concepts and personalised management. Med. J. Aust. 2018, 208, 404-409. [CrossRef]

2. Titova, N.; Chaudhuri, K.R. Personalized medicine in Parkinson's disease: Time to be precise. Mov. Disord. 2017, 32, 1147-1154. [CrossRef]

3. Ray Chaudhuri, K.; Poewe, W.; Brooks, D. Motor and Nonmotor Complications of Levodopa: Phenomenology, Risk Factors, and Imaging Features. Mov. Disord. Off. J. Mov. Disord. Soc. 2018, 33, 909-919. [CrossRef] [PubMed]

4. Leta, V.; Jenner, P.; Chaudhuri, K.R.; Antonini, A. Can therapeutic strategies prevent and manage dyskinesia in Parkinson's disease? An update. Expert Opin. Drug Saf. 2019, 18, 1203-1218. [CrossRef] [PubMed]

5. Chapuis, S.; Ouchchane, L.; Metz, O.; Gerbaud, L.; Durif, F. Impact of the motor complications of Parkinson's disease on the quality of life. Mov. Disord. Off. J. Mov. Disord. Soc. 2005, 20, 224-230. [CrossRef] [PubMed]

6. Politis, M.; Wu, K.; Molloy, S.; Bain, P.G.; Chaudhuri, K.R.; Piccini, P. Parkinson's disease symptoms: The patient's perspective. Mov. Disord. Off. J. Mov. Disord. Soc. 2010, 25, 1646-1651. [CrossRef] [PubMed]

7. Odin, P.; Ray Chaudhuri, K.; Slevin, J.T.; Volkmann, J.; Dietrichs, E.; Martinez-Martin, P.; Krauss, J.K.; Henriksen, T.; Katzenschlager, R.; Antonini, A.; et al. Collective physician perspectives on non-oral medication approaches for the management of clinically relevant unresolved issues in Parkinson's disease: Consensus from an international survey and discussion program. Parkinsonism Relat. Disord. 2015, 21, 1133-1144. [CrossRef]

8. $\quad$ Lang, A.E.; Houeto, J.L.; Krack, P.; Kubu, C.; Lyons, K.E.; Moro, E.; Ondo, W.; Pahwa, R.; Poewe, W.; Troster, A.I.; et al. Deep brain stimulation: Preoperative issues. Mov. Disord. 2006, 21 (Suppl. S14), S171-S196. [CrossRef]

9. National Instiute for Health and Care Excellence. Parkinson's Disease in Adults [NICE Guideline No. 71]. 2017. Available online: https://www.nice.org.uk/guidance/ng71 (accessed on 6 August 2021).

10. Antonini, A.; Stoessl, A.J.; Kleinman, L.S.; Skalicky, A.M.; Marshall, T.S.; Sail, K.R.; Onuk, K.; Odin, P.L.A. Developing consensus among movement disorder specialists on clinical indicators for identification and management of advanced Parkinson's disease: A multi-country Delphi-panel approach. Curr. Med. Res. Opin. 2018, 34, 2063-2073. [CrossRef] 
11. Fasano, A.; Fung, V.S.C.; Lopiano, L.; Elibol, B.; Smolentseva, I.G.; Seppi, K.; Takáts, A.; Onuk, K.; Parra, J.C.; Bergmann, L.; et al. Characterizing advanced Parkinson's disease: OBSERVE-PD observational study results of 2615 patients. BMC Neurol. 2019, 19, 50. [CrossRef]

12. Aldred, J.; Anca-Herschkovitsch, M.; Antonini, A.; Bajenaru, O.; Bergmann, L.; Bourgeois, P.; Cubo, E.; Davis, T.L.; Iansek, R.; Kovács, N.; et al. Application of the '5-2-1' screening criteria in advanced Parkinson's disease: Interim analysis of Duoglobe. Neurodegener. Dis. Manag. 2020, 10, 309-323. [CrossRef]

13. Schuepbach, W.M.; Rau, J.; Knudsen, K.; Volkmann, J.; Krack, P.; Timmermann, L.; Halbig, T.D.; Hesekamp, H.; Navarro, S.M.; Meier, N.; et al. Neurostimulation for Parkinson's disease with early motor complications. N. Engl. J. Med. 2013, 368, 610-622. [CrossRef] [PubMed]

14. Schuepbach, W.M.M.; Tonder, L.; Schnitzler, A.; Krack, P.; Rau, J.; Hartmann, A.; Halbig, T.D.; Pineau, F.; Falk, A.; Paschen, L.; et al Quality of life predicts outcome of deep brain stimulation in early Parkinson disease. Neurology 2019, 92, e1109-e1120. [CrossRef]

15. Antonini, A.; Robieson, W.Z.; Bergmann, L.; Yegin, A.; Poewe, W. Age/disease duration influence on activities of daily living and quality of life after levodopa-carbidopa intestinal gel in Parkinson's disease. Neurodegener. Dis. Manag. 2018, 8, 161-170. [CrossRef]

16. Dafsari, H.S.; Reker, P.; Silverdale, M.; Reddy, P.; Pilleri, M.; Martinez-Martin, P.; Rizos, A.; Perrier, E.; Weiß, L.; Ashkan, K.; et al. Subthalamic Stimulation Improves Quality of Life of Patients Aged 61 Years or Older with Short Duration of Parkinson's Disease. Neuromodulation J. Int. Neuromodulation Soc. 2018, 21, 532-540. [CrossRef]

17. Heald, A.H.; Livingston, M.; Stedman, M.; Wyrko, Z. Higher levels of apomorphine and rotigotine prescribing reduce overall secondary healthcare costs in Parkinson's disease. Int. J. Clin. Pract. 2016, 70, 907-915. [CrossRef]

18. Smilowska, K.; van Wamelen, D.J.; Pietrzykowski, T.; Calvano, A.; Rodriguez-Blazquez, C.; Martinez-Martin, P.; Odin, P.; Chaudhuri, K.R. Cost-Effectiveness of Device-Aided Therapies in Parkinson's Disease: A Structured Review. J. Parkinson's Dis. 2021, 11, 475-489. [CrossRef] [PubMed]

19. Schapira, A.H.V.; Chaudhuri, K.R.; Jenner, P. Non-motor features of Parkinson disease. Nat. Rev. Neurosci. 2017, 18, 435-450. [CrossRef]

20. van Wamelen, D.J.; Sauerbier, A.; Leta, V.; Rodriguez-Blazquez, C.; Falup-Pecurariu, C.; Rodriguez-Violante, M.; Rizos, A.; Tsuboi, Y.; Metta, V.; Bhidayasiri, R.; et al. Cross-sectional analysis of the Parkinson's disease Non-motor International Longitudinal Study baseline non-motor characteristics, geographical distribution and impact on quality of life. Sci. Rep. 2021, 11, 9611. [CrossRef]

21. Storch, A.; Schneider, C.B.; Wolz, M.; Sturwald, Y.; Nebe, A.; Odin, P.; Mahler, A.; Fuchs, G.; Jost, W.H.; Chaudhuri, K.R.; et al. Nonmotor fluctuations in Parkinson disease: Severity and correlation with motor complications. Neurology 2013, 80, 800-809. [CrossRef] [PubMed]

22. van Wamelen, D.J.; Leta, V.; Ray Chaudhuri, K.; Storch, A. Non-motor Fluctuations in Parkinson's Disease. In Parkinson's Disease and Movement Disorders; The Parkinson's Disease and Movement Disorder Society; in press.

23. Ray Chaudhuri, K.; Rojo, J.M.; Schapira, A.H.; Brooks, D.J.; Stocchi, F.; Odin, P.; Antonini, A.; Brown, R.G.; Martinez-Martin, P. A proposal for a comprehensive grading of Parkinson's disease severity combining motor and non-motor assessments: Meeting an unmet need. PLoS ONE 2013, 8, e57221. [CrossRef]

24. Dafsari, H.S.; Ray-Chaudhuri, K.; Mahlstedt, P.; Sachse, L.; Steffen, J.K.; Petry-Schmelzer, J.N.; Dembek, T.A.; Reker, P.; Barbe, M.T.; Visser-Vandewalle, V.; et al. Beneficial effects of bilateral subthalamic stimulation on alexithymia in Parkinson's disease. Eur. J. Neurol. 2019, 26, 222-e17. [CrossRef] [PubMed]

25. Carbone, F.; Djamshidian, A.; Seppi, K.; Poewe, W. Apomorphine for Parkinson's Disease: Efficacy and Safety of Current and New Formulations. CNS Drugs 2019, 33, 905-918. [CrossRef]

26. Martinez-Martin, P.; Reddy, P.; Katzenschlager, R.; Antonini, A.; Todorova, A.; Odin, P.; Henriksen, T.; Martin, A.; Calandrella, D.; Rizos, A.; et al. EuroInf: A multicenter comparative observational study of apomorphine and levodopa infusion in Parkinson's disease. Mov. Disord. 2015, 30, 510-516. [CrossRef] [PubMed]

27. Dafsari, H.S.; Martinez-Martin, P.; Rizos, A.; Trost, M.; Dos Santos Ghilardi, M.G.; Reddy, P.; Sauerbier, A.; Petry-Schmelzer, J.N.; Kramberger, M.; Borgemeester, R.W.K.; et al. EuroInf 2: Subthalamic stimulation, apomorphine, and levodopa infusion in Parkinson's disease. Mov. Disord. 2019, 34, 353-365. [CrossRef]

28. Deuschl, G.; Schade-Brittinger, C.; Krack, P.; Volkmann, J.; Schafer, H.; Botzel, K.; Daniels, C.; Deutschlander, A.; Dillmann, U.; Eisner, W.; et al. A randomized trial of deep-brain stimulation for Parkinson's disease. N. Engl. J. Med. 2006, 355, 896-908. [CrossRef] [PubMed]

29. Antonini, A.; Poewe, W.; Chaudhuri, K.R.; Jech, R.; Pickut, B.; Pirtosek, Z.; Szasz, J.; Valldeoriola, F.; Winkler, C.; Bergmann, L.; et al. Levodopa-carbidopa intestinal gel in advanced Parkinson's: Final results of the GLORIA registry. Parkinsonism Relat. Disord. 2017, 45, 13-20. [CrossRef] [PubMed]

30. Shalash, A.; Alexoudi, A.; Knudsen, K.; Volkmann, J.; Mehdorn, M.; Deuschl, G. The impact of age and disease duration on the long term outcome of neurostimulation of the subthalamic nucleus. Parkinsonism Relat. Disord. 2014, 20, 47-52. [CrossRef]

31. De Fabregues, O.; Dot, J.; Abu-Suboh, M.; Hernández-Vara, J.; Ferré, A.; Romero, O.; Ibarria, M.; Seoane, J.L.; Raguer, N.; Puiggros, C.; et al. Long-term safety and effectiveness of levodopa-carbidopa intestinal gel infusion. Brain Behav. 2017, 7, e00758. [CrossRef]

32. Pietz, K.; Hagell, P.; Odin, P. Subcutaneous apomorphine in late stage Parkinson's disease: A long term follow up. J. Neurol. Neurosurg. Psychiatry 1998, 65, 709-716. [CrossRef] 
33. Regidor, I.; Benita, V.; Del Álamo de Pedro, M.; Ley, L.; Martinez Castrillo, J.C. Duodenal Levodopa Infusion for Long-Term Deep Brain Stimulation-Refractory Symptoms in Advanced Parkinson Disease. Clin. Neuropharmacol. 2017, 40, 103-107. [CrossRef]

34. Kumar, N.; Murgai, A.; Naranian, T.; Jog, M.; Fasano, A. Levodopa-carbidopa intestinal gel therapy after deep brain stimulation. Mov. Disord. Off. J. Mov. Disord. Soc. 2018, 33, 334-335. [CrossRef]

35. Elkouzi, A.; Ramirez-Zamora, A.; Zeilman, P.; Barabas, M.; Eisinger, R.S.; Malaty, I.A.; Okun, M.S.; Almeida, L. Rescue levodopacarbidopa intestinal gel (LCIG) therapy in Parkinson's disease patients with suboptimal response to deep brain stimulation. Ann. Clin. Transl. Neurol. 2019, 6, 1989-1995. [CrossRef] [PubMed]

36. Bautista, J.M.P.; Oyama, G.; Nuermaimaiti, M.; Sekimoto, S.; Sasaki, F.; Hatano, T.; Nishioka, K.; Ito, M.; Umemura, A.; Ishibashi, Y.; et al. Rescue Levodopa/Carbidopa Intestinal Gel for Secondary Deep Brain Stimulation Failure. J. Mov. Disord. 2020, 13, 57-61. [CrossRef]

37. Sesar, Á.; Fernández-Pajarín, G.; Ares, B.; Relova, J.L.; Arán, E.; Rivas, M.T.; Gelabert-González, M.; Castro, A. Continuous subcutaneous apomorphine in advanced Parkinson's disease patients treated with deep brain stimulation. J. Neurol. 2019, 266, 659-666. [CrossRef] [PubMed]

38. Mulroy, E.; Leta, V.; Zrinzo, L.; Foltynie, T.; Chaudhuri, K.R.; Limousin, P. Successful Treatment of Levodopa/Carbidopa Intestinal Gel Associated "Biphasic-like" Dyskinesia with Pallidal Deep Brain Stimulation. Mov. Disord. Clin. Pract. 2021, 8, $273-274$. [CrossRef] [PubMed]

39. Zhang, X.; Xie, A. Improvement of Subthalamic Nucleus Deep Brain Stimulation in Sleeping Symptoms in Parkinson's Disease: A Meta-Analysis. Parkinsons Dis. 2019, 2019, 6280896. [CrossRef]

40. Bellini, G.; Best, L.A.; Brechany, U.; Mills, R.; Pavese, N. Clinical Impact of Deep Brain Stimulation on the Autonomic System in Patients with Parkinson's Disease. Mov. Disord. Clin. Pract. 2020, 7, 373-382. [CrossRef]

41. Cartmill, T.; Skvarc, D.; Bittar, R.; McGillivray, J.; Berk, M.; Byrne, L.K. Deep Brain Stimulation of the Subthalamic Nucleus in Parkinson's Disease: A Meta-Analysis of Mood Effects. Neuropsychol. Rev. 2021. [CrossRef] [PubMed]

42. Cavalloni, F.; Debove, I.; Lachenmayer, M.L.; Krack, P.; Pollo, C.; Schuepbach, W.M.M.; Bassetti, C.L.A.; Bargiotas, P. A case series and systematic review of rapid eye movement sleep behavior disorder outcome after deep brain stimulation in Parkinson's disease. Sleep Med. 2021, 77, 170-176. [CrossRef]

43. Maheshwary, A.; Mohite, D.; Omole, J.A.; Bhatti, K.S.; Khan, S. Is Deep Brain Stimulation Associated With Detrimental Effects on Cognitive Functions in Patients of Parkinson's Disease? A Systematic Review. Cureus 2020, 12, e9688. [CrossRef] [PubMed]

44. Jost, S.T.; Ray Chaudhuri, K.; Ashkan, K.; Loehrer, P.A.; Silverdale, M.; Rizos, A.; Evans, J.; Petry-Schmelzer, J.N.; Barbe, M.T.; Sauerbier, A.; et al. Subthalamic Stimulation Improves Quality of Sleep in Parkinson Disease: A 36-Month Controlled Study. J. Parkinson's Dis. 2021, 11, 323-335. [CrossRef]

45. Dafsari, H.S.; Ray-Chaudhuri, K.; Ashkan, K.; Sachse, L.; Mahlstedt, P.; Silverdale, M.; Rizos, A.; Strack, M.; Jost, S.T.; Reker, P.; et al. Beneficial effect of 24-month bilateral subthalamic stimulation on quality of sleep in Parkinson's disease. J. Neurol. 2020, 267, 1830-1841. [CrossRef] [PubMed]

46. Baumann-Vogel, H.; Imbach, L.L.; Surucu, O.; Stieglitz, L.; Waldvogel, D.; Baumann, C.R.; Werth, E. The Impact of Subthalamic Deep Brain Stimulation on Sleep-Wake Behavior: A Prospective Electrophysiological Study in 50 Parkinson Patients. Sleep 2017, 40. [CrossRef]

47. Irmen, F.; Horn, A.; Mosley, P.; Perry, A.; Petry-Schmelzer, J.N.; Dafsari, H.S.; Barbe, M.; Visser-Vandewalle, V.; Schneider, G.H.; Li, N.; et al. Left Prefrontal Connectivity Links Subthalamic Stimulation with Depressive Symptoms. Ann. Neurol. 2020, 87, 962-975. [CrossRef]

48. Petry-Schmelzer, J.N.; Krause, M.; Dembek, T.A.; Horn, A.; Evans, J.; Ashkan, K.; Rizos, A.; Silverdale, M.; Schumacher, W.; Sack, C.; et al. Non-motor outcomes depend on location of neurostimulation in Parkinson's disease. Brain 2019, 142, 3592-3604. [CrossRef]

49. Dafsari, H.S.; Dos Santos Ghilardi, M.G.; Visser-Vandewalle, V.; Rizos, A.; Ashkan, K.; Silverdale, M.; Evans, J.; Martinez, R.C.R.; Cury, R.G.; Jost, S.T.; et al. Beneficial nonmotor effects of subthalamic and pallidal neurostimulation in Parkinson's disease. Brain Stimul. 2020, 13, 1697-1705. [CrossRef] [PubMed]

50. Little, S.; Brown, P. What brain signals are suitable for feedback control of deep brain stimulation in Parkinson's disease? Ann. N. Y. Acad. Sci. 2012, 1265, 9-24. [CrossRef] [PubMed]

51. Florin, E.; Dafsari, H.S.; Reck, C.; Barbe, M.T.; Pauls, K.A.; Maarouf, M.; Sturm, V.; Fink, G.R.; Timmermann, L. Modulation of local field potential power of the subthalamic nucleus during isometric force generation in patients with Parkinson's disease. Neuroscience 2013, 240, 106-116. [CrossRef]

52. Imbach, L.L.; Baumann-Vogel, H.; Baumann, C.R.; Surucu, O.; Hermsdorfer, J.; Sarnthein, J. Adaptive grip force is modulated by subthalamic beta activity in Parkinson's disease patients. Neuroimage Clin. 2015, 9, 450-457. [CrossRef]

53. Hoang, K.B.; Cassar, I.R.; Grill, W.M.; Turner, D.A. Biomarkers and Stimulation Algorithms for Adaptive Brain Stimulation. Front. Neurosci. 2017, 11, 564. [CrossRef]

54. Jost, S.T.; Visser-Vandewalle, V.; Rizos, A.; Loehrer, P.A.; Silverdale, M.; Evans, J.; Samuel, M.; Petry-Schmelzer, J.N.; Sauerbier, A.; Gronostay, A.; et al. Non-motor predictors of 36-month quality of life after subthalamic stimulation in Parkinson disease. NPJ Parkinsons Dis. 2021, 7, 48. [CrossRef]

55. Wirdefeldt, K.; Odin, P.; Nyholm, D. Levodopa-Carbidopa Intestinal Gel in Patients with Parkinson's Disease: A Systematic Review. CNS Drugs 2016, 30, 381-404. [CrossRef] [PubMed] 
56. Prakash, N.; Simuni, T. Infusion Therapies for Parkinson's Disease. Curr. Neurol. Neurosci. Rep. 2020, 20, 44. [CrossRef] [PubMed]

57. Antonini, A.; Odin, P.; Pahwa, R.; Aldred, J.; Alobaidi, A.; Jalundhwala, Y.J.; Kukreja, P.; Bergmann, L.; Inguva, S.; Bao, Y.; et al. The Long-Term Impact of Levodopa/Carbidopa Intestinal Gel on 'Off'-time in Patients with Advanced Parkinson's Disease: A Systematic Review. Adv. Ther. 2021. [CrossRef] [PubMed]

58. Honig, H.; Antonini, A.; Martinez-Martin, P.; Forgacs, I.; Faye, G.C.; Fox, T.; Fox, K.; Mancini, F.; Canesi, M.; Odin, P.; et al. Intrajejunal levodopa infusion in Parkinson's disease: A pilot multicenter study of effects on nonmotor symptoms and quality of life. Mov. Disord. 2009, 24, 1468-1474. [CrossRef] [PubMed]

59. Ray Chaudhuri, K.; Antonini, A.; Robieson, W.Z.; Sanchez-Soliño, O.; Bergmann, L.; Poewe, W. Burden of non-motor symptoms in Parkinson's disease patients predicts improvement in quality of life during treatment with levodopa-carbidopa intestinal gel. Eur. J. Neurol. 2019, 26, 581-e43. [CrossRef]

60. Katzenschlager, R.; Poewe, W.; Rascol, O.; Trenkwalder, C.; Deuschl, G.; Chaudhuri, K.R.; Henriksen, T.; van Laar, T.; Spivey, K.; Vel, S.; et al. Apomorphine subcutaneous infusion in patients with Parkinson's disease with persistent motor fluctuations (TOLEDO): A multicentre, double-blind, randomised, placebo-controlled trial. Lancet Neurol. 2018, 17, 749-759. [CrossRef]

61. Todorova, A.; Ray Chaudhuri, K. Subcutaneous apomorphine and non-motor symptoms in Parkinson's disease. Parkinsonism Relat. Disord. 2013, 19, 1073-1078. [CrossRef] [PubMed]

62. Rosa-Grilo, M.; Qamar, M.A.; Evans, A.; Chaudhuri, K.R. The efficacy of apomorphine-A non-motor perspective. Parkinsonism Relat. Disord. 2016, 33 (Suppl. S1), S28-S35. [CrossRef] [PubMed]

63. Martinez-Martin, P.; Reddy, P.; Antonini, A.; Henriksen, T.; Katzenschlager, R.; Odin, P.; Todorova, A.; Naidu, Y.; Tluk, S.; Chandiramani, C.; et al. Chronic subcutaneous infusion therapy with apomorphine in advanced Parkinson's disease compared to conventional therapy: A real life study of non motor effect. J. Parkinson's Dis. 2011, 1, 197-203. [CrossRef]

64. Ellis, C.; Lemmens, G.; Parkes, J.D.; Abbott, R.J.; Pye, I.F.; Leigh, P.N.; Chaudhuri, K.R. Use of apomorphine in parkinsonian patients with neuropsychiatric complications to oral treatment. Parkinsonism Relat. Disord. 1997, 3, 103-107. [CrossRef]

65. Drapier, S.; Gillioz, A.S.; Leray, E.; Péron, J.; Rouaud, T.; Marchand, A.; Vérin, M. Apomorphine infusion in advanced Parkinson's patients with subthalamic stimulation contraindications. Parkinsonism Relat. Disord. 2012, 18, 40-44. [CrossRef] [PubMed]

66. Himeno, E.; Ohyagi, Y.; Ma, L.; Nakamura, N.; Miyoshi, K.; Sakae, N.; Motomura, K.; Soejima, N.; Yamasaki, R.; Hashimoto, T.; et al. Apomorphine treatment in Alzheimer mice promoting amyloid- $\beta$ degradation. Ann. Neurol. 2011, 69, 248-256. [CrossRef] [PubMed]

67. Antonini, A.; Isaias, I.U.; Rodolfi, G.; Landi, A.; Natuzzi, F.; Siri, C.; Pezzoli, G. A 5-year prospective assessment of advanced Parkinson disease patients treated with subcutaneous apomorphine infusion or deep brain stimulation. J. Neurol. 2011, 258, 579-585. [CrossRef] [PubMed]

68. Bouwyn, J.P.; Derrey, S.; Lefaucheur, R.; Fetter, D.; Rouille, A.; Le Goff, F.; Maltête, D. Age Limits for Deep Brain Stimulation of Subthalamic Nuclei in Parkinson's Disease. J. Parkinson's Dis. 2016, 6, 393-400. [CrossRef]

69. Levi, V.; Carrabba, G.; Rampini, P.; Locatelli, M. Short term surgical complications after subthalamic deep brain stimulation for Parkinson's disease: Does old age matter? BMC Geriatr. 2015, 15, 116. [CrossRef]

70. Dryden, M.; Baguneid, M.; Eckmann, C.; Corman, S.; Stephens, J.; Solem, C.; Li, J.; Charbonneau, C.; Baillon-Plot, N.; Haider, S. Pathophysiology and burden of infection in patients with diabetes mellitus and peripheral vascular disease: Focus on skin and soft-tissue infections. Clin. Microbiol. Infect. Off. Publ. Eur. Soc. Clin. Microbiol. Infect. Dis. 2015, 21 (Suppl. S2), S27-S32. [CrossRef]

71. Marshall, T.; Pugh, A.; Fairchild, A.; Hass, S. Patient Preferences for Device-Aided Treatments Indicated for Advanced Parkinson Disease. Value Health J. Int. Soc. Pharm. Outcomes Res. 2017, 20, 1383-1393. [CrossRef]

72. Sharma, J.C.; Lewis, A. Weight in Parkinson's Disease: Phenotypical Significance. Int. Rev. Neurobiol. 2017, 134, 891-919. [CrossRef] [PubMed]

73. Titova, N.; Ray Chaudhuri, K. Intrajejunal levodopa infusion therapy for Parkinson's disease: Practical and pragmatic tips for successful maintenance of therapy. Expert Rev. Neurother. 2017, 17, 529-537. [CrossRef] [PubMed]

74. Senek, M.; Nielsen, E.I.; Nyholm, D. Levodopa-entacapone-carbidopa intestinal gel in Parkinson's disease: A randomized crossover study. Mov. Disord. Off. J. Mov. Disord. Soc. 2017, 32, 283-286. [CrossRef] [PubMed]

75. Leta, V.; van Wamelen, D.J.; Sauerbier, A.; Jones, S.; Parry, M.; Rizos, A.; Chaudhuri, K.R. Opicapone and Levodopa-Carbidopa Intestinal Gel Infusion: The Way Forward Towards Cost Savings for Healthcare Systems? J. Parkinson's Dis. 2020, 10, 1535-1539. [CrossRef] [PubMed] 